\title{
Incidence of wound dehiscence after colorectal cancer surgery: results from a national population-based register for colorectal cancer
}

\author{
Harald Söderbäck ${ }^{1,2}$ (D) - Ulf Gunnarsson ${ }^{3} \cdot$ Anna Martling $^{4} \cdot$ Per Hellman $^{5} \cdot$ Gabriel Sandblom $^{2,6}$
}

Accepted: 1 September 2019 / Published online: 9 September 2019

(C) The Author(s) 2019

\begin{abstract}
Background Patient-related risk factors for wound dehiscence after colorectal surgery remain obscure.

Methods All open abdominal procedures for colorectal cancer registered in the Swedish Colorectal Cancer Registry (SCRCR, 5) 2007-2013 were identified. Potential risk factors for wound dehiscence were identified by cross-matching between the SCRCR and the National Patient Register (NPR). The endpoint in this study was reoperation for wound dehiscence registered in either the SCRCR or NPR and patients not reoperated were considered controls.

Results A total of 30,050 patients were included in the study. In a multivariable regression analysis, age $>70$ years, male gender, BMI $>30$, history of chronic obstructive pulmonary disease, history of generalised inflammatory disease, and duration of surgery less than 180 min were independently and significantly associated with increased risk for wound dehiscence. A history of diabetes, chronic renal disease, liver cirrhosis, and distant metastases was not associated with wound dehiscence. The hazard ratio for postoperative death was 1.24 for patients who underwent reoperation for wound dehiscence compared with that for controls.

Discussion Patients reoperated for wound dehiscence face a significantly higher postoperative mortality than those without. Risk factors include male gender, age $>70$ years, obesity, history of chronic obstructive pulmonary disease, and history of generalised inflammatory disease. Patients at high risk for developing wound dehiscence may, if identified preoperatively, benefit from active prevention measures implemented in routine surgical practice.
\end{abstract}

Keywords Wound dehiscence $\cdot$ Colorectal cancer $\cdot$ Surgery

Harald Söderbäck

harald.soderback@capiostgoran.se

1 Department of Surgery, Capio St Göran Hospital, Stockholm, Sweden

2 Department of Clinical Science and Education Södersjukhuset, Karolinska Institute, Stockholm, Sweden

3 Department of Surgical and Perioperative Sciences, Umeå University, Umeå, Sweden

4 Department of Molecular Medicine and Surgery, Karolinska Institute, Stockholm, Sweden

5 Department of Surgical Sciences, Uppsala University, Uppsala, Sweden

6 Department of Surgery, Södersjukhuset, Stockholm, Sweden

\section{Background}

Wound dehiscence is an unusual complication of abdominal surgery with high morbidity and a reported mortality rate as high as $25 \%$ [1-4]. Wound dehiscence is defined as the separation of the sutured edges of the abdominal fascia after surgery [5]. There are four principal pathogenic mechanisms resulting in wound dehiscence: rupture of the suture, knot failure, slack suture, or sutures cutting through the fascia. The last-named is considered the most common [6-8]. Wound dehiscence can be subclinical with a small dehiscence of the fascia detectable only by radiology. This form of fascial dehiscence can easily be overlooked or ignored in the early stage, but may later lead to incisional hernia formation [3]. Extensive wound dehiscence is clinically evident, with secretion from the wound and sometimes dramatic protrusion of abdominal content through the fascia, a condition known as burst abdomen. Depending on the size of the fascial defect, there is a risk for incarceration and ischaemia of the protruding viscera [9]. Wound dehiscence usually 
develops on days $3-7$ postoperatively $[10,11]$ but the diagnosis is often delayed. Symptomatic wound dehiscence is unusual, with an incidence of approximately $1 \%$ of patients undergoing elective abdominal surgery [12]. Hospital stay is significantly longer for patients suffering from wound dehiscence [13] and it is associated with considerable postoperative mortality [14]. Clinically evident wound dehiscence requires emergency surgery, which is often complicated by suboptimal condition of the patient after the index surgical procedure. At clinical examination, early wound dehiscence presents with secretion from the wound and can be mistaken for an infection. More severe cases may be diagnosed by CT scan showing dehiscence of the fascia and protrusion of viscera into the subcutaneous tissue.

There is still uncertainty regarding which patient-related factors lead to the development of wound dehiscence. There are studies that have examined risk factors for wound dehiscence $[14,15]$, but most of these are old and performed before meticulous suturing of the abdominal wall was introduced.

The aim of the present study was to analyse the incidence of wound dehiscence after colorectal cancer surgery based on a population-based national register, to identify risk factors for wound dehiscence, and to analyse mortality after wound dehiscence.

\section{Methods}

This study was based on colorectal cancer procedures performed in 2007-2013. Data were obtained from the Swedish
Colorectal Cancer Registry (SCRCR) [16]. All patients diagnosed with rectal cancer since 1995 and colon cancer since 2007 are registered in the SCRCR. The register includes data on age, gender, treatment, and postoperative follow-up. Completeness for the SCRCR is over $98 \%$ for both colon and rectal cancer, and validity compared to reabstracted data has an average agreement of $90 \%$ [17]. In addition to the SCRCR, we also used data from the National Patient Register (NPR) [18]. The NPR contains data on all hospital admissions in Sweden since 1987, including outpatient specialist care and outpatient emergency care. The validity of the NPR is estimated to be 85-90\% [19]. Diagnoses from all admissions and visits prior to the colorectal cancer surgical procedure (identified by the ICD code) were also retrieved from the NPR. The diagnoses obtained from the NPR as potential risk factors were liver cirrhosis, chronic kidney disease, diabetes with secondary complications, chronic obstructive lung disease, and generalised inflammatory disease. We also included variables such as age, gender, duration of surgery, and preoperative radiation therapy in the analyses. Crossmatching between the SCRCR and the NPR was performed using the Swedish Personal Registration Number, which is a ten-digit identity number unique for each Swedish citizen.

Reoperation for wound dehiscence is registered in the SCRCR by the surgeon responsible for the procedure. In the NPR, on the other hand, the procedure code for wound dehiscence surgery (JWA00) is recorded by the surgeon responsible for the patient at the time of discharge and then transferred to the NPR. Wound dehiscence in the present study was defined
Fig. 1 Flow chart of cohort assembly

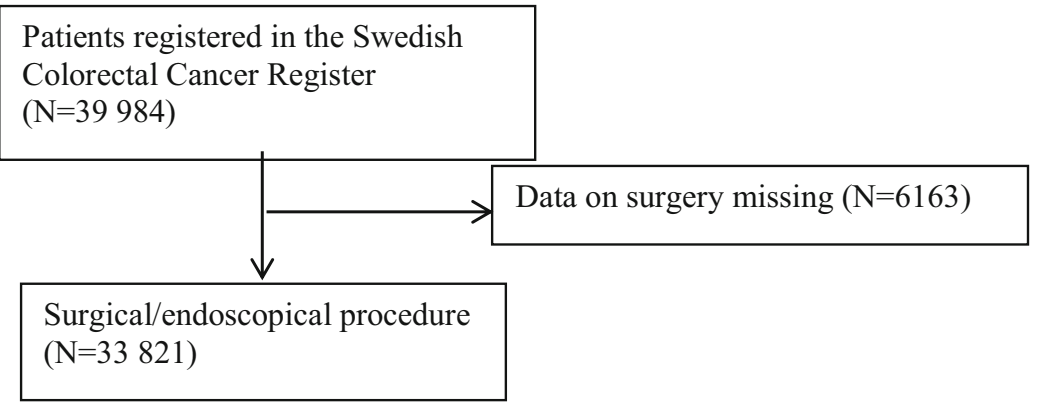

Laparoscopic procedure $(\mathrm{N}=2598)$

Type of procedure not specified $(\mathrm{N}=180)$

Appendectomy $(\mathrm{N}=58)$

Transluminal endoscopic mucosectomy $(\mathrm{N}=300)$

Local excision $(\mathrm{N}=180)$ 
as wound dehiscence registered in the SCRCR and/or the NPR, i.e. any wound dehiscence irrespective of the need for reoperation.

\section{Ethics statement}

This study was approved by the Regional Ethics Review Board in Stockholm, ref. 2014/1351-31/5.

\section{Statistics}

Statistical calculations were performed using SPSS 22.0 (Chicago, IL). Analyses were performed to assess the impact of each investigated risk factor and to estimate the incidence of wound dehiscence. Surgery for wound dehiscence was defined as discharge note or outpatient visit with the ICD code JWA00. Age, BMI, comorbid disease, presence of distant metastases, and operative time as risk factors for wound dehiscence were analysed using uni- and multivariable logistic regression analysis. Survival after reoperation for wound dehiscence was analysed with the Cox proportional hazard analysis. In a multivariate Cox proportional hazard analysis, an adjustment was made for all covariates found to increase the risk for development of wound dehiscence. The multivariate model was based on stepwise selection, with entry testing based on the significance of the score statistic and removal testing based on the probability of a likelihood ratio statistic based on the maximum partial likelihood estimates.

\section{Results}

During the study period of 2007-2013, 39,984 patients were registered in the SCRCR. After excluding patients not undergoing surgery, laparoscopic procedures, patients where data on the procedure were missing, appendectomies, transluminal endoscopic mucosectomies, and local excisions, 30,505 patients remained in the study group. The study cohort assembly flow chart is shown in Fig. 1. Baseline characteristics of the study population are shown in Table 1.

The overall incidence of reoperation for wound dehiscence after open colorectal cancer surgery was $2.9 \%$. Uni- and multivariable logistic regression analyses of potential risk factors for wound dehiscence are presented in Table 2. In the multivariable regression model, age $>70$ years, male gender, BMI $>30$, history of chronic obstructive pulmonary disease, history of generalised inflammatory disease, and operation time less than 180 min were found to be independently and significantly associated with increased risk for wound dehiscence. The single strongest risk factor was male gender (odds ratio $3.00 ; 95 \%$ confidence interval $2.52-3.57$ ). History of diabetes, chronic renal disease, liver cirrhosis, and distant metastases had no impact on the risk of wound dehiscence.

In the univariate Cox proportional hazard analysis, the hazard ratio for postoperative death was 1.24 (95\% confidence interval $1.12-1.38, p<0.001)$ for patients who underwent reoperation for wound dehiscence following the primary procedure. When adjusting for the factors found to have a significant association with wound dehiscence (age, gender, BMI, history of chronic obstructive pulmonary disease or generalised inflammatory disease, and operation time), the hazard ratio was 1.26 (95\% confidence interval 1.11-1.43, $p<0.001$ ).

Table 1 Patient characteristics

\begin{tabular}{lc}
\hline Mean age, years (standard deviation) & $71.1(11.6)$ \\
Gender & \\
Male & $15,820(51.9 \%)$ \\
Female & $14,685(48.1 \%)$ \\
BMI $\geq 30$ & $4160(13.6 \%)$ \\
Chronic obstructive pulmonary disease & $1383(4.5 \%)$ \\
Complicated diabetes & $952(3.1 \%)$ \\
Chronic kidney disease & $632(2.1 \%)$ \\
Liver cirrhosis & $78(0.3 \%)$ \\
Generalised inflammatory disease & $558(1.8 \%)$ \\
Mean operation time, minutes (standard deviation) & $207(115)$ \\
TNM classification* & \\
T & \\
0 & \\
I & $297(1.0 \%)$ \\
II & $1594(5.2 \%)$ \\
III & $4623(15.2 \%)$ \\
IV & $17,166(56.3 \%)$ \\
TX/unknown & $5746(18.8 \%)$ \\
N & $1079(3.5 \%)$ \\
0 & \\
I & \\
II & $10,783(35.3 \%)$ \\
NX/unknown & \\
M & \\
resection) & \\
Left-sided hemicolectomy (including sigmoid colon) & \\
Resection of rectum (anterior resection and & \\
I & \\
\hline
\end{tabular}

*TNM staging system colorectal cancer [26] 
Table 2 Analysis of risk for wound dehiscence

\begin{tabular}{|c|c|c|c|c|c|}
\hline \multirow[b]{2}{*}{ Variable } & \multirow[b]{2}{*}{$N$} & \multicolumn{2}{|l|}{ Univariate? logistic regression analysis } & \multicolumn{2}{|l|}{ Multivariate? logistic regression analysis } \\
\hline & & Odds ratio ( $95 \%$ confidence interval) & $p$ & Odds ratio (95\% confidence interval) & $p$ \\
\hline \multicolumn{6}{|l|}{ Gender } \\
\hline Female (ref) & $244 / 14685(1.7 \%)$ & & & & \\
\hline Male & $649 / 15820(4.1 \%)$ & $2.53(2.18-2.94)$ & $<0.001$ & $3.00(2.52-3.57)$ & $<0.001$ \\
\hline \multicolumn{6}{|l|}{ Age } \\
\hline$\leq 70$ years & $287 / 13420(2.1 \%)$ & & & & \\
\hline$>70$ years $(\mathrm{ref})$ & $606 / 17081(3.5 \%)$ & $1.68(1.46-1.94)$ & $<0.001$ & $1.72(1.46-2.02)$ & $<0.001$ \\
\hline Data on age missing & $0 / 4(0 \%)$ & & & & \\
\hline \multicolumn{6}{|l|}{ BMI } \\
\hline$<30$ & $543 / 21700(2.5 \%)$ & & & & \\
\hline$\geq 30$ & $184 / 4160(4.4 \%)$ & $1.80(1.52-2.14)$ & $<0.001$ & $1.98(1.66-2.36)$ & $<0.001$ \\
\hline Data on BMI missing & $166 / 4645(3.6 \%)$ & & & & \\
\hline \multicolumn{6}{|c|}{ Chronic obstructive pulmonary disease } \\
\hline No & $809 / 29122(2.8 \%)$ & & & & \\
\hline Yes & $84 / 1383(6.1 \%)$ & $2.26(1.80-2.85)$ & $<0.001$ & $1.98(1.52-2.58)$ & $<0.001$ \\
\hline \multicolumn{6}{|l|}{ Complicated diabetes } \\
\hline No & $863 / 29553(2.9 \%)$ & & & & \\
\hline Yes & $30 / 952(3.2 \%)$ & $1.08(0.75-1.57)$ & 0.677 & & \\
\hline \multicolumn{6}{|l|}{ Chronic renal disease } \\
\hline No & $870 / 29873(2.9 \%)$ & & & & \\
\hline Yes & $23 / 632(3.6 \%)$ & $1.26(0.83-1.92)$ & 0.284 & & \\
\hline \multicolumn{6}{|l|}{ Liver cirrhosis } \\
\hline No & $890 / 30427(2.9 \%)$ & & & & \\
\hline Yes & $3 / 78(3.8 \%)$ & $1.33(0.42-4.22)$ & 0.631 & & \\
\hline \multicolumn{6}{|c|}{ Generalised inflammatory disease } \\
\hline No & $861 / 29947(2.9 \%)$ & & & & \\
\hline Yes & $32 / 558(5.7 \%)$ & $2.01(1.43-3.00)$ & $<0.001$ & $2.27(1.49-3.45)$ & $<0.001$ \\
\hline \multicolumn{6}{|l|}{ Liver and/or lung metastases } \\
\hline Yes & $85 / 3372(2.5 \%)$ & & & & \\
\hline No & $808 / 27133(3.0 \%)$ & $0.84(0.67-1.06)$ & 0.138 & & \\
\hline \multicolumn{6}{|l|}{ Operation time } \\
\hline$\geq 180 \mathrm{~min}$ & $402 / 14754(2.7 \%)$ & & & & \\
\hline$<180 \min$ & $455 / 14525(3.1 \%)$ & $1.16(1.008-1.32)$ & 0.039 & $1.36(1.17-1.59)$ & $<0.001$ \\
\hline Data on operation time missing & $36 / 1226(2.9 \%)$ & & & & \\
\hline
\end{tabular}

\section{Discussion}

Although the incidence of wound dehiscence is reportedly only $1-2 \%$, this remains a major, potentially lethal complication after abdominal surgery. In this study, we identified risk factors for wound dehiscence that can easily be used

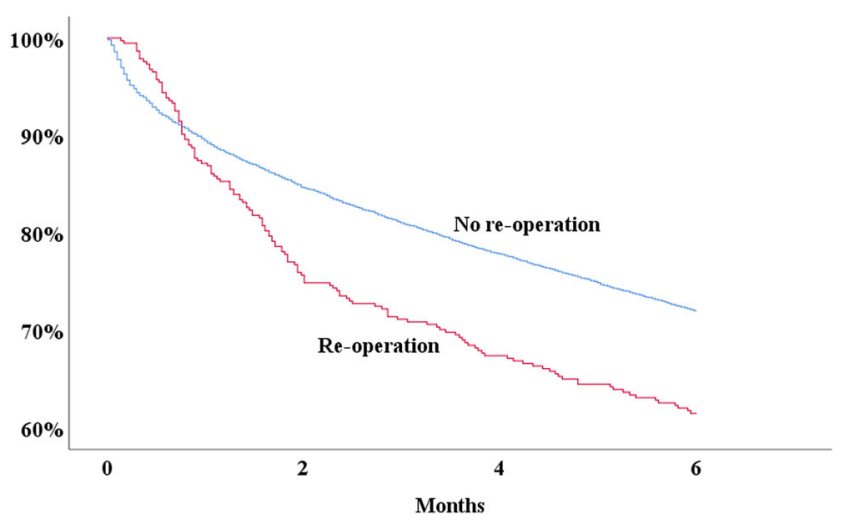

Fig. 2 Overall survival for patients undergoing and not undergoing reoperation for wound dehiscence preoperatively to identify patients at risk for wound dehiscence in order to take prophylactic measures.

This study confirms that patients reoperated for wound dehiscence face a high risk of postoperative death. Male patients, those older than 70 years, patients with high BMI, or suffering from chronic obstructive pulmonary disease or generalised inflammatory disease have a higher risk for wound dehiscence than those in the general population. There is also an increased risk if the time taken at the index operation is less than $180 \mathrm{~min}$.

During the study period of 2007-2013, surgery for colorectal cancer was mainly performed via a midline incision, and we therefore believe that this study provides a good estimate of the complication rate following midline incisions. This is also why we excluded laparoscopic surgery from the study.

There are, however, some limitations to this study. Surgery for colorectal cancer is performed on a heterogeneous group of patients. Our material includes acute, elective, curative, and palliative surgery. Most procedures are performed through a midline incision, but there could be cases in this cohort that were operated through an incision having a lower predicted 
incidence of complications such as a transverse or Pfannenstiel incision [20]. Furthermore, the length of the incision probably varied.

The surgical technique used to close the midline incision is probably a major risk factor for wound dehiscence. The modern technique introduced by Milbourn et al. [21-23] was introduced in Sweden during the study period, but no specific data on surgical technique were available in the SCRCR. The incidence of wound dehiscence after open colorectal cancer surgery in this study was $2.2 \%$ which is close to the findings of Kenig et al. [14] and Webster et al. [24] who reported the incidence to be $2 \%$ and $3 \%$, respectively. In a study on 750 patients in 2009, Milbourn et al. [21] presented a modernised technique for closing midline incisions which has now become a standard [8]. In their study, there was only one case of wound dehiscence. Nicholas et al. [12] report the incidence of wound dehiscence to be $0.4-1.2 \%$ in elective surgery and $12 \%$ in acute surgery. This indicates that future studies on wound dehiscence must take surgical technique and acute or elective surgery into account. Our present study confirms the higher postoperative mortality rate for patients with wound dehiscence which is in accordance with previously reported studies such as those of Nicholas et al. [12]. From previous studies, we know that hospital stay is longer for patients with wound dehiscence [13]. Although wound dehiscence is an unusual complication, risk stratification and prophylactic measures are worthwhile since the suffering and cost of every case is so vast.

The study showed a hazard ratio of 1.26 for mortality risk when a wound dehiscence was registered. The actual increase in risk, however, is probably even higher. There may have been deaths in the early postoperative period where wound dehiscence was the main cause or contributing factor, but where no attempt to resuture the abdominal wall was made. In these cases, the wound dehiscence may not have been registered. This could explain the paradoxically higher survival for the first 7 days after surgery for patients who underwent surgery for wound dehiscence (Fig. 2).

Short operation duration as a risk factor for complication seems counter-intuitive and contradicts other studies [25]. A feasible explanation for this could be that palliative surgery and diagnostic surgery where you decide the tumour to be inoperable fall in this category. Operating time as a risk factor needs to be further investigated.

In conclusion, wound dehiscence is associated with a higher postoperative mortality rate. Patients at high risk for developing dehiscence may benefit from active prevention measures if these can be implemented in routine surgical practice. In this respect, the knowledge that male gender, age $>70$ years, obesity, history of chronic obstructive pulmonary disease, and history of generalised inflammatory disease are risk factors makes identification of patients at risk possible.
Funding information Open access funding provided by Karolinska Institute. This study was made possible by the financial support from the Novus Scientific and by a grant from the Capio Research Foundation.

\section{Compliance with ethical standards}

This study was approved by the Regional Ethics Review Board in Stockholm, ref. 2014/1351-31/5.

Open Access This article is distributed under the terms of the Creative Commons Attribution 4.0 International License (http:// creativecommons.org/licenses/by/4.0/), which permits unrestricted use, distribution, and reproduction in any medium, provided you give appropriate credit to the original author(s) and the source, provide a link to the Creative Commons license, and indicate if changes were made.

\section{References}

1. Burger JW, Lange JF, Halm JA, Kleinrensink GJ, Jeekel H (2005) Incisional hernia: early complication of abdominal surgery. World $\mathrm{J}$ Surg 29(12):1608-1613. https://doi.org/10.1007/s00268-0057929-3

2. Henriksen NA (2016) Systemic and local collagen turnover in hernia patients. Dan Med J 63(7):B5265

3. Pollock AV, Evans M (1989) Early prediction of late incisional hernias. Br J Surg 76(9):953-954

4. Xing L, Culbertson EJ, Wen Y, Franz MG (2013) Early laparotomy wound failure as the mechanism for incisional hernia formation. $\mathrm{J}$ Surg Res 182(1):e35-e42. https://doi.org/10.1016/j.jss.2012.09. 009

5. Ellis H (2010) Applied anatomy of abdominal incisions. Br J Hosp Med (Lond) 71(3):M36-M37. https://doi.org/10.12968/hmed. 2010.71.Sup3.46991

6. Cox PJ, Ausobsky JR, Ellis H, Pollock AV (1986) Towards no incisional hernias: lateral paramedian versus midline incisions. J R Soc Med 79(12):711-712

7. Guillou PJ, Hall TJ, Donaldson DR, Broughton AC, Brennan TG (1980) Vertical abdominal incisions-a choice? Br J Surg 67(6): 395-399

8. Muysoms FE, Antoniou SA, Bury K, Campanelli G, Conze J, Cuccurullo D, de Beaux AC, Deerenberg EB, East B, Fortelny RH, Gillion JF, Henriksen NA, Israelsson L, Jairam A, Janes A, Jeekel J, Lopez-Cano M, Miserez M, Morales-Conde S, Sanders DL, Simons MP, Smietanski M, Venclauskas L, Berrevoet F, European Hernia S (2015) European Hernia Society guidelines on the closure of abdominal wall incisions. Hernia 19(1):1-24. https:// doi.org/10.1007/s10029-014-1342-5

9. Carlson MA (1997) Acute wound failure. Surg Clin North Am 77(3):607-636

10. Luijendijk RW, Jeekel J, Storm RK, Schutte PJ, Hop WC, Drogendijk AC, Huikeshoven FJ (1997) The low transverse Pfannenstiel incision and the prevalence of incisional hernia and nerve entrapment. Ann Surg 225(4):365-369

11. Rath AM, Attali P, Dumas JL, Goldlust D, Zhang J, Chevrel JP (1996) The abdominal linea alba: an anatomo-radiologic and biomechanical study. Surg Radiol Anat : SRA 18(4):281-288

12. Slater NJ, Bleichrodt RP, van Goor H (2012) Wound dehiscence and incisional hernia. Surgery (Oxford) 30(6):282-289. https://doi. org/10.1016/j.mpsur.2012.03.001

13. Mäkelä JT, Kiviniemi H, Juvonen T, Laitinen S (1995) Factors influencing wound dehiscence after midline laparotomy. Am J 
Surg 170(4):387-390. https://doi.org/10.1016/S0002-9610(99) 80309-2

14. Kenig J, Richter P, Zurawska S, Lasek A, Zbierska K (2012) Risk factors for wound dehiscence after laparotomy - clinical control trial. Pol Przegl Chir 84(11):565-573. https://doi.org/10.2478/ v10035-012-0094-0

15. Aksamija G, Mulabdic A, Rasic I, Aksamija L (2016) Evaluation of risk factors of surgical wound dehiscence in adults after laparotomy. Mediev Archaeol 70(5):369-372. https://doi.org/10.5455/medarh. 2016.70.369-372

16. SCRCR. https://www.cancercentrum.se/samverkan/ cancerdiagnoser/tjocktarm-andtarm-och-anal/tjock\%2D\%2Dochandtarm/kvalitetsregister/

17. Moberger P, Skoldberg F, Birgisson H (2018) Evaluation of the Swedish Colorectal Cancer Registry: an overview of completeness, timeliness, comparability and validity. Acta Oncol (Stockholm, Sweden) 57(12):1611-1621. https://doi.org/10.1080/0284186x. 2018.1529425

18. National Patient registry. https://www.socialstyrelsen.se/register/ halsodataregister/patientregistret/inenglish

19. Ludvigsson JF, Andersson E, Ekbom A, Feychting M, Kim JL, Reuterwall C, Heurgren M, Olausson PO (2011) External review and validation of the Swedish national inpatient register. BMC Public Health 11:450. https://doi.org/10.1186/1471-2458-11-450

20. Orcutt ST, Balentine CJ, Marshall CL, Robinson CN, Anaya DA, Artinyan A, Awad SS, Berger DH, Albo D (2012) Use of a Pfannenstiel incision in minimally invasive colorectal cancer surgery is associated with a lower risk of wound complications. Tech Coloproctol 16(2):127-132. https://doi.org/10.1007/s10151-0120808-7
21. Millbourn D, Cengiz Y, Israelsson LA (2009) Effect of stitch length on wound complications after closure of midline incisions: a randomized controlled trial. Arch Surg 144(11):1056-1059. https:// doi.org/10.1001/archsurg.2009.189

22. Millbourn D, Cengiz Y, Israelsson LA (2011) Risk factors for wound complications in midline abdominal incisions related to the size of stitches. Hernia 15(3):261-266. https://doi.org/10. 1007/s10029-010-0775-8

23. Millbourn D, Israelsson LA (2004) Wound complications and stitch length. Hernia 8(1):39-41. https://doi.org/10.1007/s10029-0030159-4

24. Webster C, Neumayer L, Smout R, Horn S, Daley J, Henderson W, Khuri S, National Veterans Affairs Surgical Quality Improvement P (2003) Prognostic models of abdominal wound dehiscence after laparotomy. J Surg Res 109(2):130-137

25. Soderback H, Gunnarsson U, Hellman P, Sandblom G (2018) Incisional hernia after surgery for colorectal cancer: a populationbased register study. Int J Color Dis 33(10):1411-1417. https://doi. org/10.1007/s00384-018-3124-5

26. Bertero L, Massa F, Metovic J, Zanetti R, Castellano I, Ricardi U, Papotti M, Cassoni P (2018) Eighth edition of the UICC classification of malignant tumours: an overview of the changes in the pathological TNM classification criteria - what has changed and why? Virchows Arch 472(4):519-531. https://doi.org/10.1007/s00428017-2276-y

Publisher's note Springer Nature remains neutral with regard to jurisdictional claims in published maps and institutional affiliations. 